American Journal of Infectious Diseases 5 (4): 314-319, 2009

ISSN 1553-6203

(C) 2009 Science Publications

\title{
Determination of the Salivary Anti-Phenolic Glycolipid-1 Antibody in Leprosy Patients as a Tool to Monitoring Multidrugtherapy
}

\author{
${ }^{1}$ N.L.B. Bonfitto, ${ }^{1}$ A.C.F. Motta, ${ }^{1}$ R.B. Furini, ${ }^{2}$ M.C. Komesu, \\ ${ }^{1}$ M.M.P. do Nascimento, ${ }^{1}$ J.F.C. Figueiredo and ${ }^{1}$ N.T. Foss \\ ${ }^{1}$ Department of Internal Medicine, Medical School of Ribeirão Preto, \\ Universidade of São Paulo, Ribeirão Preto-SP, Brazil \\ ${ }^{2}$ Department of Morphology, Stomatology and Physiology, \\ Dental School of Ribeirão Preto, University of São Paulo, Ribeirão Preto-SP, Brazil
}

\begin{abstract}
Problem statement: The upper airways has a great importance as a route of $M$. leprae infection and because of the possibility of identifying relevant tools by systematic patient evaluation, the detection of leprosy patients by means of salivary markers becomes important. The aim of this study was to analyze anti-phenolic glycolipid 1 (anti-PGL-1) salivary and serum titers as parameters for correlation with infection, antigen exposure and treatment response. Approach: Leprosy patients before, during and after specific treatment for leprosy were selected. Salivary and serum anti-PGL-1 levels were determined by Enzyme-Linked Immunosorbent Assay (ELISA) in 30 leprosy patients ranging in age from 17-71 years old (mean: 48.45 \pm 20.92 years) and in 10 healthy controls ranging in age from 22-45 years old (mean: $32.2 \pm 9.23$ years). Data were analyzed statistically by Analysis Of Variance (ANOVA). Results: There were significant differences in serum anti-PGL-1 titers between leprosy patients and healthy controls $(\mathrm{p}<0.05)$; however, significant differences in salivary anti-PGL1 (IgA and $\operatorname{IgM}$ ) were found only between non-treated leprosy patients and healthy controls. MB patients showed higher serum (IgM) and salivary (IgA) levels of anti-PGL-1 than PB patients. Conclusion/Recommendations: The serum and salivary measurements of anti-PGL-1 antibody may be useful in evaluating antigen exposure and MDT response and in distinguishing MB from PB patients.
\end{abstract}

Key words: saliva, anti-PGL-1, leprosy, Mycobacterium leprae

\section{INTRODUCTION}

Leprosy is a chronic infectious disease caused by Mycobacterium leprae, an acid-fast bacillus that presents a peculiar tropism for peripheral nerves and the skin. The prevalence of leprosy in the world has declined since the introduction of the Multi-Drug Therapy (MDT) recommended by the World Health Organization (WHO $)^{[1]}$. However, leprosy is still a public health problem, especially in Brazil, where the number of new cases detected is high (38.914 cases in $2008)^{[2]}$.

The predominant route of leprosy transmission is from the contaminated patient's upper airways to a new $\operatorname{host}^{[3]}$, thus emphasizing the importance of mucosal lesion control. The nasal mucosa can be affected in the early stages of the disease $\mathrm{e}^{[4,5]}$ and oral involvement appears in the advanced stages, a fact suggesting the hematogenic or lymphatic dissemination of $M$. leprae. Leprosy-specific oral lesions are generally asymptomatic ulcers or nodules sometimes rich in $M$. leprae ${ }^{[6,7]}$ resembling nonspecific oral lesions, but they can maintain the focus of infection in endemic areas.

The diagnosis of leprosy is based on clinical, Bacterial Index (BI) and histopathological findings ${ }^{[8]}$ and serological determination of the antibodies. The Phenolic Glycolipid antibody (PGL-1), determined by Enzyme-Linked Immunosorbent Assay (ELISA), has been considered an relevant marker of leprosy activity. The PGL-1 fraction is part of the cell envelope of $M$. leprae and induces the production of the humoral specific response against PGL-1 detected in patient serum $^{[9,10]}$. When the antibody is present at high levels, the infection can be supposed to be active, especially

Corresponding Author: Ana Carolina Fragoso Motta, Departamento of Internal Medicine, Medical School of Ribeirão Preto, Universidade de São Paulo, Av. Bandeirantes, 3900, CEP: 14049-900, Ribeirão Preto, SP-Brazil Tel/Fax: +55 - 16 - 36330236 
during the reactional episodes, which constitute a very common complication in the evolution of leprosy ${ }^{[11,12]}$.

Because of the importance of the upper airways (nasal and oral) as a route of $M$. leprae infection and because of the possibility of identifying relevant tools by systematic patient evaluation, the detection of salivary markers becomes important, especially considering humoral immunity mediators such as $M$. leprae-specific anti-PGL-I antibody in leprosy patients. Thus, the aim of this study was to analyze serum and salivary titers of anti-PGL-1 antibody as parameters for correlation with antigen exposure and treatment response.

\section{MATERIALS AND METHODS}

Patients: Thirty leprosy patients $(20 \mathrm{men}$ and 10 women, mean \pm SD age $48.45 \pm 20.92$ years; range 17 $71)$ and 10 healthy controls (5 men and 5 women, mean \pm SD age 32.2 \pm 9.23 years; range 22-45) participated in the study (Table 1). The leprosy patients selected before, during and after MDT-WHO were attended at the Leprosy Clinics of the School of Medicine of Ribeirão Preto, University of São Paulo. The diagnosis of leprosy was made based on clinical and histopathological findings ${ }^{[8]}$, BI, biopsy and the determination of serum anti-PGL1 antibody. Patients were grouped following the operational classification (WHO) into Multibacillary (MB) those who presented $\mathrm{BI}$ bigger than 3+ and Paucibacillary (PB), those with negative BI. The healthy controls were selected at the Dentistry School of Ribeirão Preto of University of São Paulo. Subjects were excluded if they presented a history of salivary gland cancer, Sjögren syndrome, use of xerogenic drugs and if they did not give informed consent. The trial was approved by the local Ethics Committee and all subjects gave written informed consent to participate.

Study groups: Patients were divided into 4 groups: group I-10 patients who had not received specific treatment for leprosy; group II-10 patients who had received and concluded the specific treatment for leprosy; group III-10 patients studied during the specific treatment for leprosy; groups IV-10 healthy patients, non-communicants of leprosy patients, who represented the control group.

Saliva collection: As $5 \mathrm{~mL}$ of non-stimulated saliva was collected from each subject into a sterile container over a period of $5 \mathrm{~min}$. The collected saliva was immediately centrifuged at $4500 \mathrm{rpm}$ for $30 \mathrm{~min}$ at
$4{ }^{\circ} \mathrm{C}$, divided into $500 \mu \mathrm{L}$ aliquots and stored at $-70^{\circ} \mathrm{C}$ until the time for analysis. The samples were obtained between 8:00 and 10:00 am. The patients were instructed not to eat or drink, not to smoke or brush their teeth $1 \mathrm{~h}$ before the saliva collection in order to minimize the risks of contamination.

Serum antibody titers: Ninety-six-well polystyrene plates (Costar, Cambridge, USA) were coated with antigen (PGL-1; kindly provided by Dr. J.S. Spencer, Colorado University, USA) in sodium carbonate buffer $\left(2 \mu \mathrm{g} \mathrm{mL} \mathrm{m}^{-1}\right), \mathrm{pH} 9.6$ and stored at $4^{\circ} \mathrm{C}$ until used. Serum from each patient was diluted 1:100 in $15 \mathrm{mM}$ Tris-Tween buffer containing 5\% sheep serum, $10 \mu \mathrm{L}$ were added to each well and the plate was incubated for $1 \mathrm{~h}$ at $37^{\circ} \mathrm{C}$ in a humid chamber. At the end of this period, the samples were washed with $15 \mathrm{mM}$ Tris-Tween buffer and anti-human IgM betagalactosidase conjugate (Sigma, USA) diluted 1:600 in $15 \mathrm{mM}$ Tris-Tween buffer containing 5\% sheep serum was added. The plates were then incubated at $37^{\circ} \mathrm{C}$ for $1 \mathrm{~h}$. A fluorigenic substrate $(10 \mu \mathrm{L} 4$ methylumbelliferyl beta-D-galactopyranoside) was then added to the samples and the material was incubated at $37^{\circ} \mathrm{C}$ for $30 \mathrm{~min}$. The plate was read with a multiskan ELISA reader. Sera with an absorbance at $450 \mathrm{~nm}$ greater than 0.028 (the mean absorbance plus three standard deviations of 40 healthy Brazilian control subjects) were considered positive. Each serum was tested in duplicate.

Salivary antibody titers: Salivary anti-PGL1 levels were determined by ELISA using 96-well polystyrene plates (Costar, Cambridge, USA). The plates were coated with antigen (PGL-1) in sodium carbonate buffer $(3 \mu \mathrm{g} / 10 \mathrm{~mL})$ for $24 \mathrm{~h}$ at $4^{\circ} \mathrm{C}$. Saliva from each patient was diluted 1:4 in PBS-Tween, $100 \mu \mathrm{L}$ were added to each well and the plate was incubated for 1 $1 / 2 \mathrm{~h}$ at room temperature. After washing, goat antihuman IgA and mouse anti-human IgM alkalinephosphatase conjugates (Sigma, USA) diluted 1:250 and 1:100 in PBS-T-0.05\%, respectively, were added to the wells and incubated for $1 \mathrm{~h}$ at room temperature. The plates were washed and incubated for $15 \mathrm{~min}$ at room temperature with a substrate solution containing p-nitrophenyl phosphate. The reaction was stopped with $3 \mathrm{M} \mathrm{NaOH}$. The concentrations of the antigen, saliva and conjugate were standardized based on serial dilutions in order to obtain ideal concentrations for the assay. In addition, 
the different incubation times and temperatures, the number of wash cycles and the different antigen dilutions were standardized. Absorbance was determined at $450 \mathrm{~nm}$. Data are reported as Optical Density (OD) values minus the blank.

Statistical analysis: One-way Analysis of Variance (ANOVA) with Friedman test was used to compare the serum and salivary anti-PGL-1 levels between the groups (I, II, III and healthy controls) and Wilcoxon test was used to compare the serum and salivary antiPGL-1 between PB and MB patients with the aid of the GraphPad Prism software (San Diego, CA, USA). Significance was set at $\mathrm{p}<0.05$.

\section{RESULTS}

Serum antibody titers: Serum anti-PGL-1 IgM antibody was significantly higher in leprosy patients (groups I, II and III) compared to healthy controls (group IV) ( $\mathrm{p}<0.05$, Fig. 1). The highest anti-PGL-1 values were found in samples from non-treated patients. The analysis based on clinical form showed significantly higher anti-PGL-1 levels in MB than in PB patients (Table 2).

Salivary antibody titers: The salivary anti-PGL-1 IgA antibodies of group I leprosy patients were significantly higher than those of healthy controls (group IV) $(\mathrm{P}=0.003$; Table 2 and Fig. 2a) and the anti-PGL-1 IgA salivary antibody showed high levels than $\operatorname{IgM}$ antibody.

When the analysis was made based on the operational classification in the MB patients $(n=21)$ were found to have higher salivary $(\operatorname{IgA})$ and serum anti-PGL-1 values than in PB patients $(n=09)$. There



was no significant difference in salivary anti-PGL-1 (IgM) between groups (Table 2 and Fig. 2b).

Table 1: Clinical data of the leprosy patients (Groups I-III) and healthy controls

\begin{tabular}{llllllll}
\hline & & Personal data & & & \\
& & & & & \\
& Patients & & & Sex & & Race & \\
& (N) & Age (years) & M & F & W & AD & A \\
\hline Group I & 10 & $46.30 \pm 17.11$ & 06 & 04 & 05 & 05 & 00 \\
Group II & 10 & $53.10 \pm 17.78$ & 07 & 03 & 05 & 04 & 01 \\
Group III & 10 & $46.60 \pm 12.80$ & 07 & 03 & 07 & 03 & 00 \\
Group IV & 10 & $32.20 \pm 9.23$ & 05 & 05 & 09 & 00 & 01 \\
Total & 40 & $44.55 \pm 16.05$ & 25 & 15 & 26 & 12 & 02 \\
\hline
\end{tabular}

M: Male; F: Female; W: White; AD: African descent; A: Asian

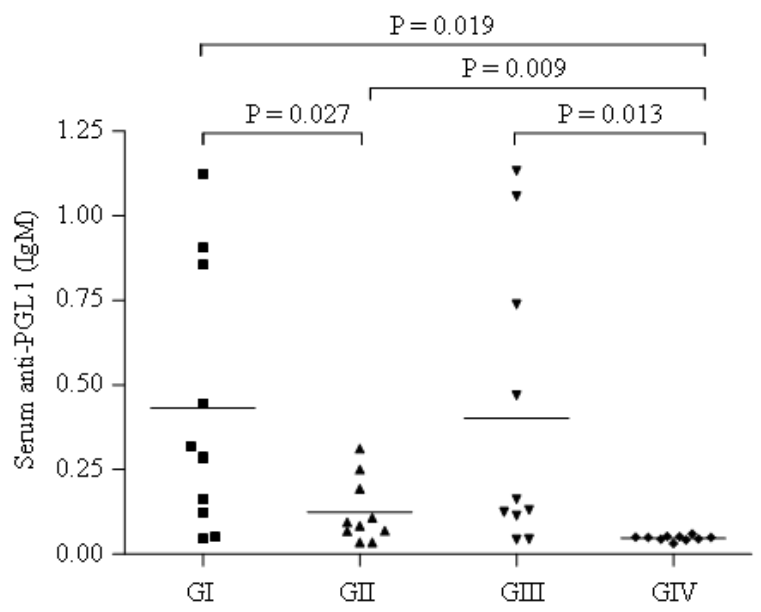

Fig. 1: Serum anti-PGL-1 (IgM) levels from leprosy patients before, during and after MDT (GI, GII, GIII) and from healthy controls (GIV). The horizontal lines represent the mean of each group



Fig. 2: ( $\mathrm{a}$ and b): Salivary anti-PGL-1 (IgA and IgM) levels from leprosy patients before, during and after MDT (GI, GII, GIII) and from healthy controls (GIV). The horizontal lines represent the mean of each group 
Am. J. Infect. Dis., 5 (4): 314-319, 2009

Table 2: Serum and salivary anti-PGL-1 levels (mean \pm SD) in leprosy patients and healthy controls by treatment group and by the operational clinical classification of leprosy

\begin{tabular}{llllllr}
\hline & Group I & Group II & Group III & Group IV & PB $(\mathrm{n}=9)$ & MB $(\mathrm{n}=21)$ \\
\hline Serum IgM & $0.432 \pm 0.391^{*}$ & $0.124 \pm 0.094^{\Pi}$ & $0.401 \pm 0.300^{\sharp}$ & $0.047 \pm 0.007$ & $0.090 \pm 0.057^{\dagger}$ & $0.397 \pm 0.393$ \\
Salivary IgA & $0.176 \pm 0.118^{\text {\# }}$ & $0.172 \pm 0.123$ & $0.158 \pm 0.118$ & $0.082 \pm 0.062$ & $0.113 \pm 0.105^{\ddagger}$ & $0.204 \pm 0.113$ \\
Salivary IgM & $0.035 \pm 0.043$ & $0.043 \pm 0.048$ & $0.025 \pm 0.022$ & $0.020 \pm 0.024$ & $0.032 \pm 0.045$ & $0.033 \pm 0.037$ \\
\hline
\end{tabular}

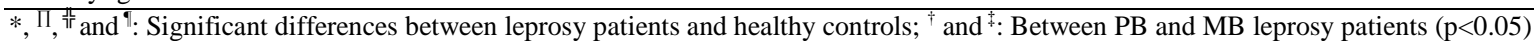

\section{DISCUSSION}

The mucosal defense function against $M$. leprae infection is not clear; however, it is known that local immunity is the first defense line against M. leprae, which consists of secretion of antimicrobial peptides and antigen-specific antibodies of the immunoglobulin class. These events have been previously described in saliva by some authors ${ }^{[13-15]}$, who demonstrated elevation of salivary immunoglobulin secretion in leprosy patients and household contacts. The detection of antibodies in saliva represents the expression of local immunity ${ }^{[14,16]}$, but their presence is not sufficient to block the process of $M$. leprae infection ${ }^{[15,17]}$. However, we believe that this local immunity may protect the oral mucosa against $M$. leprae since the oral mucosa is rarely affected by $M$. leprae $e^{[18]}$.

This study assessed the levels of anti-PGL-1 antibody in serum and saliva samples, a tool that can be used as an adjunct to the determination of antigen exposure and to the clinical monitoring of leprosy patients on MDT. Our results showed significantly higher levels of serum anti-PGL-1 IgM in non-treated leprosy patients than in healthy controls, as demonstrated by ${ }^{[10,19-21]}$. On the other hand, the institution of MDT seems to reduce anti-PGL1 levels (Fig. 1). Measuring M. leprae-specific serum anti-PGL1 antibody has been considered useful in monitoring leprosy patients on $\mathrm{MDT}^{[19,21]}$.

The results of salivary anti-PGL1 (IgA) determination for non-treated patients were similar to those obtained in the serum test when compared with healthy controls. When MDT was initiated there was a decrease of salivary (IgA/IgM) anti-PGL1 levels. This finding allows us to deduce that salivary anti-PGL-1 determination can produce results as useful as those obtained by the serum test in patients before treatment and in danger risk groups. In addition, this observation may be related to the efficacy of MDT and suggests that the measurements of salivary $M$. leprae-specific antibodies during MDT may be used to determine the effectiveness of leprosy treatment.

The half-life of mucosal IgA and IgM plasma cells in the epithelium is very short and $\operatorname{IgA}$ antibodies inhibit the activation of the classical pathway by $\operatorname{IgM}$ antibodies recognizing the same antigen ${ }^{[22]}$, a fact that might be attributed to competition between IgA and other isotypes for antigen binding sites or to interference with the availability of the initial classical pathway components $^{[23,24]}$. Thus, we can explain the fact that antiPGL-1 IgA levels were higher than IgM levels.

Serum anti-PGL1 antibody has been reported to be higher in MB than in PB patients ${ }^{[10,19,21,25]}$. Similarly, we found higher serum and salivary (IgA) anti-PGL-1 antibody levels in MB patients than in PB patients. This can be explained by the limited sensitivity of this test in detecting PB leprosy patients ${ }^{[25]}$, probably by insufficient quantity of PGL-1 antigen in mucosal surfaces to induce a local immune response ${ }^{[16]}$.

The results suggest a useful role for the measurement of salivary M. leprae-specific anti- PGL1 IgA antibody, which can be used as an easy, noninvasive and inexpensive method to detect leprosy in the population and to monitor the response to MDT, as reported previously ${ }^{[26]}$. In addition, the results suggest an important role for the measurement of serum anti-PGL-I antibodies in distinguishing MB from PB leprosy, as demonstrated by Silva et al. ${ }^{[19]}$ and Oskam et al. ${ }^{[25]}$ and the possibility of using the saliva test instead of the serum test.

\section{CONCLUSION}

The presence of mucosal antibodies suggests that the PGL-1 antigen induced a local immune response and these increased antibody concentrations may be associated with protection of mucosal surfaces, but not with blocking M. leprae multiplication in the host ${ }^{[17,26]}$. Studies on a larger number of patients are necessary to confirm this hypothesis and to verify the validity of measuring anti-PGL-1 IgA antibody levels in serial salivary samples from patients to monitor the leprosy spectrum during the course of MDT. In conclusion, serum and salivary measurements of anti-PGL-1 IgA antibody may be useful in evaluating antigen exposure and MDT response and in distinguishing MB from $\mathrm{PB}$ patients.

\section{ACKNOWLEDGMENT}

We thank the National Council for Scientific and Technological Development-CNPq (grant 
124992/2008-0) and the Sao Paulo State Foundation against Leprosy (grant 111) for financial support and Mr Mario Ignácio Neto and Mr Gilberto André e Silva for assistance with sample analysis.

\section{REFERENCES}

1. Manglani, P.R., M.A. Arif, 2006. Multidrug therapy in leprosy. J. Indian Med. Assoc., 104: 686-688.

http://www.ncbi.nlm.nih.gov/17474286

2. World Health Organization, 2009. Global leprosy situation. Wkly Epidemiol. Rec., 84: 333-340. http://www.ncbi.nlm.nih.gov/19685606

3. Scheepers, A., 1998. Correlation of oral surface temperatures and the lesion of leprosy. Int. J. Lepr. Other. Mycobact. Dis., 66: 214-217. http://www.ncbi.nlm.nih.gov/pubmed/9728454

4. Araújo, M.G., 2003. Hanseníase no brasil. Rev. Soc. Bras. Med. Trop., 36: 373-382. DOI: 10.1590/S0037-86822003000300010

5. Foss, N.T., 1999. Leprosy: clinical, immunological and therapeutical aspects Ann. Bras. Dermatol. 74: 113-119.

http://www.anaisdedermatologia.org.br/public/artig o.aspx? id=299

6. Motta, A.C.F., M.C. Komesu and C.H.L. Silva et al., 2008. Leprosy-specific oral lesions: A report of three cases. Med. Oral Patol. Oral Cir. Bucal, 13: E479-E482.

http://www.medicinaoral.com/medoralfree01/v13i8 /medoralv13i8p479.pdf

7. Chimenos, K.E., M. Pascual Cruz, C. Pinol Dansis, H. Vinals Iglesias, M.E. Rodríguez de Rivera Campillo and J. López López, 2006. Lepromatous leprosy: A review and case report. Med. Oral Patol. Oral Cir. Bucal, 11: E474-E479. http://www.medicinaoral.com/medoralfree01/v11i6 /medoralv11i6p474.pdf

8. Ridley, D.S. and W.H. Jopling, 1966. Classification of leprosy according to immunity: A five group system. Int. J. Lepr., 34: 255-273. http://www.ncbi.nlm.nih.gov/pubmed/5950347

9. Cho, S.N., D.L. Yanagihara, S.W. Hunter, R.H. Gelber and P.J. Brennan, 1983. Serological specificity of phenolic glycolipid-I from Mycobacterium leprae and use in serodiagnosis of leprosy. Infect. Immun., 41: 1077-1083. http://iai.asm.org/cgi/reprint/41/3/1077

10. Foss, N.T., F. Callera and F.L. Alberto, 1993. AntiPGL1 levels in leprosy patients and their contacts. Braz. J. Med. Biol. Res., 26: 43-51. http://www.ncbi.nlm.nih.gov/pubmed/8220267
11. Chin-A-Lein, R.A., W.R. Faber, M.M. van Rens, D.L. Leiker, B. Naafs and P.R. Klatser, 1992. Follow-up of multibacillary leprosy patients using phenolic glycolipid-I based ELISA. Do increasing ELISA-values after discontinuation of treatment indicate relapse? Lepr. Rev., 63: 21-27. http://www.ncbi.nlm.nih.gov/pubmed/1569812

12. Goulart, I.M.B., G.O. Penna and G. Cunha, 2002. Immunopathology of leprosy: the complexity of the mechanisms of host immune response to Mycobacterium leprae. Rev. Soc. Bras. Med. Trop., 35: 365-375. DOI: 10.1590/S003786822002000400014

13. Ahmed, H.A., J. Touw, G.L. Stoner and A. Belehu, 1983. Imunoglobulin A (IgA) in nasal washings and saliva of leprosy patients. Int. J. Lepr., 51: 22-28. http://www.ncbi.nlm.nih.gov/6683256

14. Abe, M., Y. Yoshino and F. Minagawa et al., 1984. Salivary immunoglobulins and antibody activities in leprosy. Int. J. Lepr., 52: 343-350. http://www.ncbi.nlm.nih.gov/6541202

15. Cree, I.A., S. Sharpe, N.D. Sturrock, I.H. Cochrane, W.C. Smith and J.S. Beck, 1988. Mucosal immunity to mycobacteria in leprosy patients and their contacts. Lepr. Rev., 59: 309-316. http://www.ncbi.nlm.nih.gov/3072455

16. Nagao-Dias, A.T., T.L.P. Almeida, M.F. Oliveira, R.C. Santos, A.L. Lima and M. Brasil, 2007. Salivary anti-PGL-1 and IGA titers and serum antibody $\mathrm{IgG}$ titers and activities in leprosy patients and their correlation with time of infection and antigen exposure. Braz. J. Infect. Dis., 11: 215-219. DOI: $10.1590 / 51413-86702007000200009$

17. Touw, J., E.JM. Langendiyk, G.L. Stoner and A. Belehu, 1982. Humoral immunity in leprosy: immunoglobulin $\mathrm{G}$ and $\mathrm{M}$ antibody responses to Mycobacterium leprae in relation to various disease patterns. Infect. Immun., 36: 885-892. http://iai.asm.org/cgi/reprint/36/3/885?view=long\& pmed $=7047400$

18. Smith, W.C., C.M. Smith and I.A. Cree et al., 2004. An approach to understanding the transmission of Mycobacterium leprae using molecular and immunological methods: results from the MILEP2 study. Int. J. Lepr. Other Mycobact. $\quad$ Dis., $\quad$ 72: 317-319. http://www.ncbi.nlm.nih.gov/15485283

19. Silva, E.A., A. Iyer and S. Ura et al., 2007. Utility of measuring serum levels of anti-PGL-I antibody, neopterin and $\mathrm{C}$-reactive protein in monitoring leprosy patients during multi-drug treatment and reactions. Trop. Med. Int. Health, 12: 1450-1458. DOI: $10.1111 / \mathrm{j} .1365-3156.2007 .01951 . x$ 
20. Stefani, M.M.A., C.M.T. Martelli, O.L. Morais-Neto, P. Martelli, M.B. Costa and A.L.S.S. Andrade, 1998. Assessment of anti-PGL-1 as a prognostic marker of leprosy reaction. Int. J. Lepr., 66: 356-364. http://www.ncbi.nlm.nih.gov/9934362

21. Zenha, E.M., M.A. Ferreira and N.T. Foss, 2009. Use of anti-PGL-1 antibodies to monitor therapy regimes in leprosy patients. Braz. J. Med. Biol. Res., 42: 968-972. DOI: 10.1590/S0100879X2009001000016

22. Griffiss, J.M. and D.K. Goroff, 1983. IgA blocks IgM and IgG-initiated immune lysis by separate molecular mechanisms. J. Immunol., 130: 2882-2885. http://www.jimmunol.org/cgi/reprint/130/6/2882

23. Marcotte, H. and M.C. Lavoie, 1998. Oral microbial ecology and the role of salivary immunoglobulin A. Microbiol. Mol. Biol. Rev., 62: 71-109.

http://mmbr.asm.org/cgi/reprint/62/1/71
24. Salvi, S. and S.T. Holgate, 1999. Could the airway epithelium play an important role in mucosal immunoglobulin A production? Clin. Exp. Alergy, 29: 1597-1605. DOI: $10.1046 /$ j.13652222.1999.00644.x

25. Oskam, L., E. Slim and S. Buhrer-Sekula, 2003. Serology: recent developments, strengths, limitations and prospects: a state of the art overview. Lepr. Rev., 74: 196-205. http://www.ncbi.nlm.nih.gov/14577464

26. Kaplan, M.H. and M.W. Chase, 1980. Antibodies to Mycobacterium in human tuberculosis. II. Response to nine defined mycobacterial antigen with evidence for an antibody common to tuberculosis and lepromatous leprosy. J. Infec. Dis., 142: 835-843. http://www.ncbi.nlm.nih.gov/6780633 